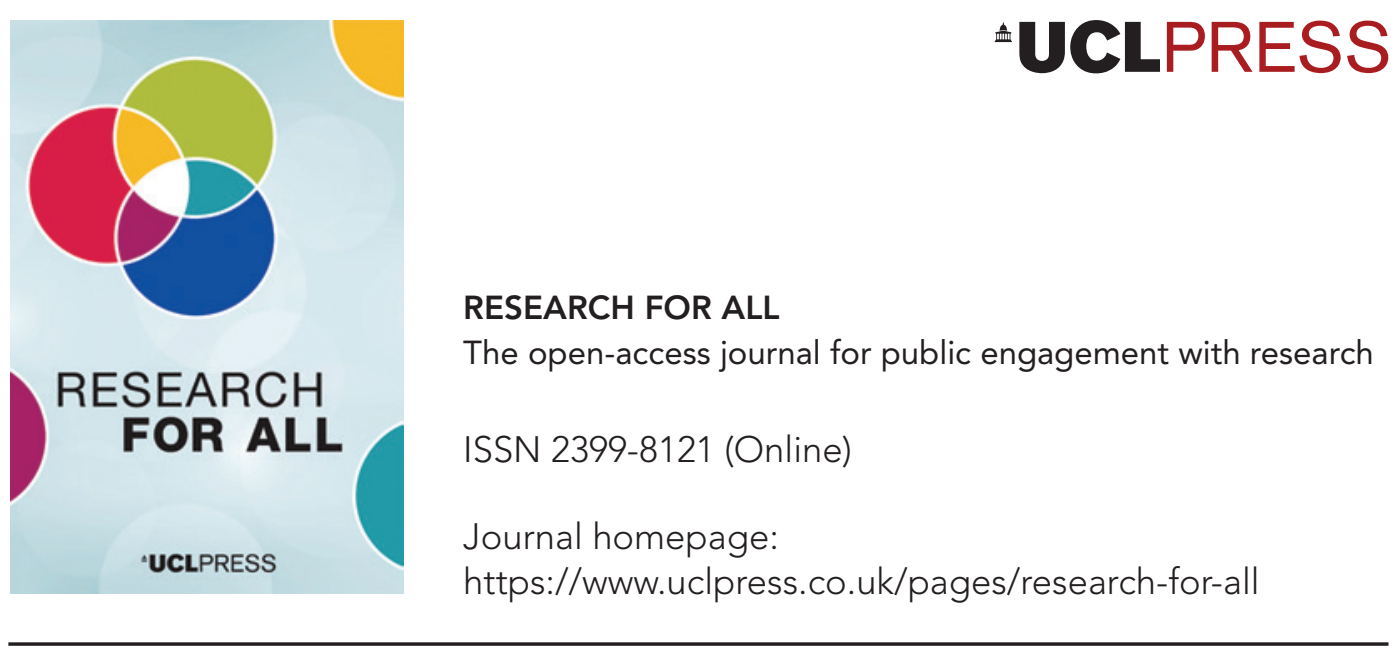

\title{
Small grants, big impact: The Institute of Classical Studies' seed funding scheme for public engagement
}

\section{Emma Bridges ic}

\section{How to cite this article}

Bridges, E. (2021) 'Small grants, big impact: The Institute of Classical Studies' seed funding scheme for public engagement'. Research for All, 5 (2), 290-301. https://doi. org/10.14324/RFA.05.2.07

Submission date: 18 October 2020

Acceptance date: 14 May 2021

Publication date: 21 September 2021

\section{Peer review}

This article has been peer-reviewed through the journal's standard double-blind peer review, where both the reviewers and authors are anonymized during review.

\section{Copyright}

(C) 2021 Bridges. This is an open-access article distributed under the terms of the Creative Commons Attribution Licence (CC BY) 4.0 https://creativecommons.org/licenses/by/4.0/, which permits unrestricted use, distribution and reproduction in any medium, provided the original author and source are credited.

\section{Open access}

Research for All is a peer-reviewed open-access journal. 


\title{
Small grants, big impact: The Institute of Classical Studies' seed funding scheme for public engagement
}

\author{
Emma Bridges* - The Open University, UK
}

\begin{abstract}
This case study provides details of a small-grants scheme (delivered by the Institute of Classical Studies since 2018) which is designed to support researchers in classics and related subjects to undertake activities whereby they are able to share their research with non-specialist audiences (that is, people who do not already have an academic knowledge of the field in which they are researching). It outlines the practicalities of running such a scheme, describes the outcomes and impact which the scheme has had to date, and concludes by offering recommendations for organizations which may be considering setting up such a grant programme specifically to support public engagement with academic research. The lessons learned as a result of this scheme could be readily applied to other academic disciplines (particularly - but not limited to - those with an arts and humanities focus which share characteristics with classics) or institutional contexts.
\end{abstract}

Keywords: seed corn funding, small grants, pilot funding schemes, arts and humanities research, public engagement, classics

\section{Key messages}

- In providing a reflective case study on a small-grants scheme for public engagement, this article offers a model which could be adopted by individuals and institutions wishing to implement such a scheme.

- Small amounts of money (up to $f 500$ in this case) can help to generate impactful arts and humanities public engagement projects.

- There is a need for more seed corn funding for public engagement, particularly in connection with arts and humanities research.

\section{Introduction}

This case study focuses on a UK-wide subject-specific grant programme for researchers in classics and related subjects which provides seed corn funding of up to $f 500$ per application for public engagement activities. The lessons learned as a result of this scheme, which is administered by the Institute of Classical Studies (ICS), could readily be applied in other contexts, both disciplinary and institutional. I offer the reflections in this article in the hope of providing others with evidence to support the delivery of other such funding programmes. The article outlines the practicalities of running such a scheme, describes the outcomes and impact of the ICS initiative, and concludes 
by offering recommendations for organizations which may be considering setting up such a grant programme specifically to support public engagement with academic research. My particular focus is on the practicalities of providing funding for public engagement with arts and humanities research, for which even small-scale financial support is not always readily available. The interdisciplinary nature of classics, which encompasses (among other sub-disciplines) the study of cultures, languages, history, archaeology, philosophy and literatures, means that the lessons learned from this case study can be readily applied to other areas of study within the arts and humanities.

The provision of financial support for public engagement with research in the UK varies widely between disciplinary and institutional contexts. Where the arts and humanities are concerned, national funding bodies tend only to offer large-scale grants for public engagement, rather than seed corn funding for pilot projects. For example, the British Academy's Mid-Career Fellowships (British Academy, n.d. a) provide support for public engagement as part of an applicant's research. Only those already in secure academic employment are eligible to apply, however, as the fellowships fund salary costs (up to $f 80,000$ over a maximum of 12 months). An earlier British Academy scheme which focused on public engagement, the Rising Star Engagement Awards (BARSEA), made smaller amounts of money available ( $₫ 15,000$ per applicant), but again, there were limits on eligibility: candidates were expected to be no further than ten years from the award of their doctorate (British Academy, n.d. b). This scheme no longer operates. The Arts and Humanities Research Council (AHRC) offers a scheme designed to support public engagement with grants of up to $f 100,000$, yet this is a 'follow-on funding' scheme open only to those who have already been in receipt of a major AHRC research grant (UKRI, 2020). Even without the barriers relating to eligibility criteria, the application processes for grants such as these are time-consuming and success rates are low. For example, the most recent statistics published by the AHRC (UKRI and AHRC, 2021), referring to the academic year 2017/18, indicate that the overall success rate of applications to all of their grant schemes is 27 per cent. This rises to 53 per cent (21 of 40 applicants) for the follow-on funding scheme for public engagement, yet applicants to this scheme must already have been successful in applying for an earlier research grant from the AHRC.

The major research funders in the UK rarely make available small grants, with light-touch application processes, specifically for public engagement. One exception is the Science and Technology Facilities Council (STFC), which ran a Small Awards Scheme from 2013 to 2016, making grants of between $£ 500$ and $£ 10,000$ available for science communication projects; this scheme has now ended, however. Reports on each of the awards rounds are available (UKRI and STFC, 2018). No comparable national scheme has yet been offered by any of the UK-wide funding bodies which support arts and humanities research.

For researchers who require small sums of money to trial a public engagement idea or run a small-scale project, many higher education institutions run schemes which operate on a local level. However, it can be difficult for those seeking to learn from others' good practice in administering such grant programmes to access information about their mechanics, outcomes and impact. Not all institutions make the details publicly available, and often the only way to locate the relevant information is by trawling individual institutional websites or reports submitted for the Knowledge Exchange Framework (see UKRI, 2021). Some universities do advertise the terms of their schemes and showcase the work of grant recipients on their institutional pages, or provide details of the funded projects in annual reviews, but even the fact that different institutions use a range of terminology for their funding schemes can make a 
systematic search challenging. Funding which can be accessed for public engagement work is not always directly described as such by institutions, but may be categorized as being related to 'research and innovation', 'impact' or 'knowledge exchange', for example. The range of offerings provided by individual institutions includes:

- The University of Bath uses a blog to publicize details of projects which have been funded by its Engage Grants, which offer various levels of funding, from $£ 200$ for 'start-up' projects to larger grants of between $£ 5,000$ and $£ 10,000$ (University of Bath Public Engagement Unit, 2021).

- The University of Bristol's Temple Quarter Engagement Fund makes awards of between $£ 3,000$ and $£ 5,000$, and makes available very brief summaries of the projects which it supports (University of Bristol Public Engagement, 2021).

- Goldsmiths, University of London's latest Public Engagement Review indicates that in 2019, approximately $£ 6,000$ in grants, ranging in value from $£ 300$ to $£ 1,000$, was awarded to eight different researchers, and provides a summary of each project (Goldsmiths, University of London, 2019).

- The University of Southampton offers 'Development Funding' for Public Engagement with Research, making grants of between $£ 500$ and $£ 4,000$ per project proposal, and sharing a bank of case studies of funded activities (University of Southampton Public Engagement with Research unit, 2021).

It is rarely possible, however, to access full evaluations of these small-grant schemes, and this can make it difficult for those who wish to make a robust case for the implementation of a similar initiative to locate supporting evidence.

One exception to this lack of published evaluations relates to the national Being Human festival. Being Human's annual evaluation reports (Being Human, 2021) give full financial statistics and details of the impact of the festival. Being Human makes available small grants (usually up to $£ 1,500$ per event) for public engagement activities run in conjunction with the festival. However, as Being Human is an annual event, funded activities must take place during the festival itself (in November each year). For humanities researchers who are unable to undertake public engagement during this time, or whose work does not fit in with the theme of the festival, other sources of funding are needed.

\section{Context}

The Institute of Classical Studies is one of nine humanities research institutes which together form the School of Advanced Study (SAS) at the University of London. The remit of the ICS, in keeping with that of the SAS more widely, is 'to promote and facilitate research in classical studies in the widest possible terms throughout the UK and beyond, and to do so with special attention to encouraging interdisciplinary and innovative research' (ICS, 2015: n.p.). One aspect of this is to contribute to the public understanding of research in classics by organizing events and activities aimed not only at subject specialists, but also at audiences who may not otherwise have opportunities to engage with academic research, and by supporting colleagues elsewhere to do the same. In 2017, the ICS appointed, for the first time, a Public Engagement Fellow for a period of three years. Lack of further available funding meant that the ICS was unable to renew the post after 2020. The fellow's responsibilities included supporting researchers working on classics and related subjects to undertake high-quality public engagement in order to share their research with publics beyond academia. The author of this article occupied the role of Public Engagement Fellow from 2017 to 2020. 
This case study focuses on one of the key initiatives of the ICS, which was designed to support public engagement projects undertaken by UK-based researchers: a small-grants scheme providing seed funding (up to $£ 500$ per application) to enable academics to test out public-facing projects based on their research. The format used was modelled on an existing light-touch grant scheme by which the ICS supports academic conferences. The new scheme was designed to fill a gap in the availability of national funding programmes which offer small grants for public engagement. In particular, it was conceived as a means of providing support for researchers who are otherwise unable (for reasons relating to precarious employment, lack of institutional funds, or ineligibility/lack of capacity to apply for some of the larger national research awards) to fund even small-scale public engagement projects. The deadline for the first round of applications to the ICS public engagement grants scheme was in January 2018. At the time of drafting this article (September 2020), five subsequent funding rounds had taken place, and it was expected that the scheme would continue to operate on a twice-yearly basis so long as funding was available.

\section{Administering the grant scheme}

Given the relatively small sums of money involved, and the already considerable pressures on researchers' time, it was decided early on that a light-touch approach would be appropriate. In keeping with the scope of the funds available, and the ICS's own remit, the criteria for eligibility state that applicants must be UK-based researchers. This definition includes research students and independent researchers (for whom, without an institutional affiliation, access to funding is often especially problematic), as well as those employed in higher education institutions. Fundable activities must demonstrate aspects of research in classics (broadly defined) in ways that are accessible, enjoyable and understandable for non-specialist audiences. Public lectures and school talks are not normally eligible on the grounds that, in the case of the former, these offer fewer opportunities for two-way engagement with non-specialist audiences, and, in the case of the latter, other sources of funding are usually available to classicists. Applicants are also advised that projects involving a collaboration with external partners will have the greatest chance of success. Possible external partners include: creative practitioners; community groups or charities; heritage organizations; museums, libraries or galleries; and schools.

Applicants to the scheme are expected to complete a short form, where they are required to respond under several headings:

(1) Please provide a 300-500 word summary of your proposed public engagement activity. This should specify the academic research to which the activity is linked, as well as giving an indication of the intended audience and approximate dates. Applicants should explain here what they anticipate to be the likely benefits for both the researcher(s) and the public(s) with whom the research will be shared.

(2) Give details of any external partners to be involved in the activity (for example, community organizations, creative practitioners, heritage professionals, libraries/ galleries/museums, schools). Please indicate whether you have already secured a provisional commitment from suggested partners.

(3) Please explain briefly (up to 250 words) how you plan to build on the proposed engagement activity in future (for example, by using it to inform future research, by developing further public events or by reaching out to different publics).

Applicants are also asked to provide an estimate of costs for elements of their project, and to give details of any other funding which has already been secured or applied for. 
Where possible, funded activities are expected to be provided free of charge to those attending. This is not necessarily possible in all cases, so if a charge is to be made, grant recipients are asked to offer discounts or exemptions to those who are unwaged. It is made clear on the application form that the ICS grants can be used to cover the following types of costs (this is not an exhaustive list, but is indicative of the kinds of things for which the fund may be used): professional fees (for example, for creative practitioners or non-academic advisers); costs for venue hire in a public location; hire or purchase of specialist equipment; consumables, including catering if this is a core aspect of an event, but not, for example, for drinks receptions.

Applications are considered by a small committee, and decisions are communicated to all applicants within one month of the deadline, but often much sooner. This swift turnaround is helpful in order to enable successful applicants to proceed with planning their activities. Unsuccessful applicants are offered the opportunity to receive feedback if they wish. Administrative support for the scheme, in relation to collating applications, communicating outcomes and making the necessary financial arrangements, is provided by the ICS's Institute Manager. Between 2018 and 2020, successful applicants were able to draw on the support of the Public Engagement Fellow for informal mentoring, should they wish to do so. In some cases, applicants did not require any additional assistance. In others, this support could take the form of, for example, the provision of advice about event formats and delivery, help with building networks of contacts with relevant experience, or assistance with the promotion of awardees' public engagement activities.

As a condition of receiving funding, all successful applicants are required to write a short report on their funded activity in the form of an article for the ICS blog (ICS, 2017). This serves several purposes: it builds a public-facing record of the impact of the scheme; it offers grant-holders a platform from which to share their work with both the academic community and wider publics; and it creates an online archive where those seeking ideas for their own public engagement work can find inspiration.

\section{Outcomes and impact: Scope of grants awarded}

Between January 2018 (the first deadline for applications) and May 2020, 53 applications to the grant scheme were received. Of these, 27 funding bids were successful; a total of $f 11,820.53$ was disbursed, with grants ranging from $f 130$ to the maximum allowable amount of $f 500$. No limit is set by the ICS as to the number of times an individual or project can apply to the scheme, on the basis that a project which has been funded once may still benefit from further financial support once proof of concept has been established. Six applicants benefited from the scheme more than once, although in the case of two of the applicants this was for two different projects rather than repeat funding for an extension of their first project. Successful applications were predominantly characterized by the following: a demonstrable link between current research and the proposed public engagement activity; collaboration with one or more non-academic partners (for example, a creative practitioner, heritage organization, school or cultural institution); a clearly defined target audience (for example, in terms of demographic characteristics, interests or location); and a clear plan setting out how the money would be spent. Some applications did not meet the stated criteria for the grants. In some cases, for example, the proposed activities would be classed as outreach rather than public engagement with research, and therefore they fell outside the scope of the ICS's own funding remit. In others, the target audience was composed predominantly of academics who were already familiar with the area of research being 
shared. This in itself was instructive, however, as it enabled the grant-awarding panel to consider what the ICS might do to correct some of the common misconceptions within the academic community about public engagement with research, its purpose and target audiences. One outcome of this is a free self-study course, Introduction to Public Engagement with Research, written by Emma Bridges for the Institute of Classical Studies, which is available online (see School of Advanced Study, University of London, 2019).

Activities funded by the scheme have been connected with a wide range of research topics across the span of sub-disciplines covered by researchers working on classics (including, for example, archaeology, ancient history, classical reception, art history, literary texts, ancient languages and theatre). There has also been a geographical spread of applications from researchers based in England and Scotland, although noticeably, at the time of writing this article, there had been no applications to the scheme from researchers based in Wales or Northern Ireland. Nonetheless, the scheme has proved to be one way in which the ICS can fulfil its remit to support colleagues who are not within easy reach of London, where the ICS is located - for example, successful applications came from researchers based at the universities of Manchester, Newcastle, St Andrews and Glasgow, and from Manchester Metropolitan University and Liverpool Hope University. To September 2020, applications to the scheme had been received from researchers affiliated with 22 of the higher education institutions in the UK where classical subjects are taught and researched, and successful applicants came from 15 institutions. (In total, there are 37 institutions currently teaching and researching classical subjects, counted according to their association with the Council of University Classical Departments - see CUCD (2021) for a full list.) Community partners with whom researchers funded by the scheme have worked include creative practitioners (among them visual artists, storytellers, theatre companies, actors, videographers and musicians), museums, local archaeological societies, libraries, schools, the University of the Third Age (U3A) and other community organizations. By May 2020, around sixty community partners had been involved in collaborating on the funded projects. The formats of projects varied, with some activities operating as in-person events and others designed for delivery online.

Projects funded by the scheme include the following (this provides a representative sample of the range of topics, formats, audiences and partners, rather than an exhaustive list):

- Athena's Owls (led by PhD students Kat Mawford and Matt Ingham): a project working with local libraries in Manchester to share research on ancient myth with children aged 5-11 and their families.

- Rematerialising Mosul Museum (led by Dr Zena Kamash): a project using crafting and textiles to respond to the destruction of Iraqi cultural heritage, working in particular with British Iraqis.

- Ancient Greek for All with Barefaced Greek (led by Dr Helen Eastman): subtitling new high-quality films enacting scenes from ancient Greek drama (performed in the original language) in five languages (aimed primarily at a teenage audience, but accessible to any audience with an interest in theatre and performance).

- Autism and Classical Mythology (led by Professor Susan Deacy): a workshop in Roehampton with specialists on autism and child development to develop resources based on ancient myth aimed at autistic children.

- Greek Comedy in Action (led by Dr Rosie Wyles): a series of events in Kent in partnership with the University of the Third Age to introduce retired members of the community to the plays of Aristophanes. 
- The Minotaur in British Sign Language (led by Dr Liz Gloyn): a partnership with artist and storyteller Howard Hardiman to retell the myth of the Minotaur for deaf audiences, using British Sign Language.

- Recreating a Roman Garden (led by Dr Patricia Baker): a partnership with the Trust for Thanet Archaeology to create a community garden based on Roman garden design.

In June 2020, a survey was circulated to all previous grant awardees via the online platform SurveyMonkey. It was completed by 15 grant recipients, who supplied further information about the progress of their projects and reflected on the impact which the ICS grant had had on their work. Respondents were asked to estimate the audience numbers which their projects had reached to date (or were likely to reach, in the case of recent awardees who had not yet undertaken their funded project). A simple totalling of the numbers reported or estimated indicated that the face-to-face events delivered by these respondents alone had already attracted in the region of fifteen thousand members of the public. Activities ranged from small-scale workshops and theatre performances, with audiences of 25 to 50, up to partnerships with museums attracting many thousands of visitors. One exhibition created in collaboration with the Freud Museum in London had nine thousand visitors; another, which is yet to take place at Vindolanda Museum in Northumberland, is also expected to reach numbers in the thousands. For activities which take place online, in-depth or two-way engagement can be harder to measure by looking at numbers alone, but those who supplied statistics for web page visits, podcast listens and YouTube views reported significant reach. One podcast featuring classical research had 11,140 listens at the time of reporting, a YouTube video demystifying the ancient historian Thucydides had been watched 1,437 times, and a blog reporting on the Autism and Classical Mythology project had been accessed 78,000 times.

\section{Outcomes and impact: Feedback from grant recipients}

The survey also asked recipients to reflect on some of the ways in which the grant had impacted on their own work. To the question, 'In what ways has the ICS public engagement grant benefited your project?', the 15 respondents answered as set out in Table 1. (Respondents chose answers from a list, with no limit to how many answers could be selected by each respondent.)

Table 1: Responses to the question, 'In what ways has the ICS public engagement grant benefited your project?'

\begin{tabular}{lll}
\hline Answer choice & $\%$ & $\begin{array}{c}\text { Number (out of } \\
\text { 15 respondents) }\end{array}$ \\
\hline It enabled me to reach a new audience with my research & 73 & 11 \\
It enabled me to deepen my understanding of public engagement & 73 & 11 \\
It facilitated collaboration with a new community partner & 67 & 10 \\
It helped me to make the case for additional funding from elsewhere & 67 & 10 \\
It generated new interest in my work from within academia & 60 & 9 \\
It helped me to develop new skills & 47 & 7 \\
My employer now takes my public engagement work more seriously & 27 & 4 \\
It enabled me to try public engagement for the first time & 13 & 2 \\
\hline
\end{tabular}


Respondents were also given space to provide free-text comments, which in some cases elaborated further on their responses to the above question. Several indicated that the grant had given them an opportunity to launch a project which could not have happened without the funding they were given, or that it enabled them to test out ideas on which they could build for future work. One referred to the scheme as 'an excellent kickstarting opportunity', and another commented that 'The scheme has been absolutely critical to getting this project off the ground.'

In some other cases, comments reflected on the importance of the funding for the community partners too, for example, in situations where a grant facilitated the payment of fees to a creative practitioner (one project lead said that 'the financial support has been such a boon to the theatre company'), or allowed for the purchase of materials and equipment which would otherwise have been unaffordable for small community organizations with little funding. Some recipients also noted the importance of being able to share their research with new audiences as a result of their funded project. As one person wrote: '[My project] allowed people who would normally never have any interest in the ancient world to become enthusiastic about Classics because I could relate it to their expertise and passions.'

Some also reported that the work which had been funded by the grant scheme had directly informed the future path of their research. One recipient commented that:

... staging this play was decisive in figuring out possible ways to improve the reconstruction of the fragmentary tragedy Melanippe Wise, informing my academic commentary on the play too (which I am currently finalising); thus the original research this event was based on is now informed and updated through the outcome of the reading and the feedback I received...

Another wrote:

The scheme took my project to a new level and is informing what I've done since, including now writing a book whose approach and contents are impacted by what happened at the event I was enabled to run.

In several cases, recipients indicated that the small project funded by the grant scheme had led to further expansion of their public engagement activities. For some, this had been in the form of invitations from other interested parties to share their work with more new audiences, or the motivation to find different ways of engaging people with their topic. For example, one reported that they were now writing an accessible book for a non-specialist audience, as well as creating a new public engagement project on a theme related to their original work. Some of those who had created reusable resources such as videos or podcasts suggested that they were finding new ways of employing these, sometimes in their teaching, as well as for further public engagement activities. One awardee also shared news of how their project had gained further attention from other academics, as well as from the public, and as a result had expanded geographically:

The PE [public engagement] grant we received has been invaluable for the success of Athena's Owls and we are extremely grateful to have received it. It has not only allowed us to expand the project and made a huge impact on the project's reach and visibility (to the point where we now have three separate hubs), but has also inspired us to continue trying to expand and improve the project. 
Other recipients referred to particular practical skills which they had acquired (for example, event organization, video editing or scriptwriting) as a result of carrying out their funded project, or specialist knowledge which they had been able to develop through working with their community partners.

In particular, several awardees also indicated that the opportunity to write a short article describing their work for the ICS blog (see ICS, 2017) had enabled them to inform other members of the academic community about their project, and that this had then led to further discussions about the work with colleagues and potential new collaborators. Although the blog itself had only 153 subscribers at the time of writing this article, posts reach a wider audience of those with a prior interest in classics through dissemination on Twitter and via the Facebook group Classics International (which has around twelve thousand members). Blogposts relating to public engagement shared by Emma Bridges (from her personal account, @emmabridges) and by the ICS official account (@ICSDirector) on Twitter were usually seen by between three thousand and five thousand Twitter users, attracting upwards of fifty direct interactions (link clicks or comments).

\section{Outcomes and impact: Further funding successes}

As indicated above (Table 1), ten of the people who responded to the follow-up survey suggested that receipt of a grant from the ICS had enabled them to make the case for additional funding from elsewhere, either from institutions to which they are affiliated or from other grant-awarding bodies. One told us: 'The fact that I had the grant meant I could make a case to my Head of Department and College Director of Research to persuade them to commit to additional funding.' In other cases, small additional grants had been won from other organizations with a connection to classics, including the Classical Association, the Hellenic Society and the Gilbert Murray Trust. For some, having the money to pay creative practitioners' fees meant that they were then also able to secure support in kind from host venues. Some were also successful in winning larger sums of money, with one project securing a total of $£ 4,600$ (in two separate grants) from Arts Council England. In terms of scale, however, the most striking impact has been that generated by one grant recipient, Dr Zena Kamash, who used her funded project as proof of concept in order to help secure a substantial award from the British Academy under the terms of the 2019 Heritage, Dignity and Violence Programme. This major project, which began life in 2018 as Rematerialising Mosul Museum with an ICS grant of $£ 500$, is called Crafting Heritage for Well-Being in Iraq, and has been granted funding of $£ 227,813.50$ by the British Academy (Heritage, Dignity \& Violence Programme, 2019). Kamash's report on the initial ICS-funded workshops is available on the ICS blog (Kamash, 2018).

In one other unanticipated development, the grants scheme attracted the attention of an anonymous donor, who was inspired to make a financial gift, with the instruction that this was to be used to support classics-related public engagement in the UK in whatever way the ICS deemed to be appropriate. The gift enabled the ICS to run a one-off awards scheme in 2020, whereby two outstanding public engagement projects were given financial support to develop their work further. Further details of the recipients of these awards are available on the ICS blog (Bridges, 2020).

\section{Recommendations}

The ICS small-grants scheme has, with relatively small financial outlay and low administrative load, made a significant difference to the delivery of classics-related 
public engagement by researchers based in the UK. This is evidenced by the number of projects funded, the variety of types of engagement activity, the range of audiences and community partners engaged, and the geographical spread of the funded work being undertaken. In addition, the feedback provided by grant recipients illustrates that a seed funding programme such as this can provide the necessary springboard for researchers to get started with public engagement projects, which in many cases have then garnered further support and interest, so that the work can develop, expand or inspire more new projects. The practicalities of this scheme are relatively simple, and therefore it would be easily replicable in other contexts, whether in the case of national subject centres/organizations, or at a more local/institutional level where such initiatives do not yet exist. Although the example given relates specifically to classics, the core principles of excellent public engagement are the same across disciplines, and so there should be no barriers to using a similar approach for other subject areas.

I conclude by offering some practical recommendations for organizations or individuals who may be considering implementing a similar funding programme in their own setting:

- If funds are limited, providing several grants for small amounts can be more effective than simply funding one or two larger bids. The ICS scheme has shown that $f 500$ can go a long way towards getting an excellent project off the ground; in many cases, recipients needed less than this.

- Simplify the application process as much as possible. This includes: ensuring that applicants do not need to fill in large amounts of paperwork (which also minimizes the demands on the awarding panel's time); having a regular cycle of deadlines; and communicating outcomes as quickly as possible and in accordance with an advertised timescale.

- Offer unsuccessful applicants the opportunity to receive feedback if possible. This enables them to develop their understanding of effective public engagement, and provides them with guidance on refining their application should future funding opportunities arise.

- If resources allow, an opportunity for awardees to receive mentoring from someone with detailed knowledge and experience of public engagement is beneficial. This can also be done in a relatively light-touch way. As well as providing support if the recipient requires this, it allows the opportunity for the grant-making body to keep in touch regarding future developments relating to the funded project.

- Providing the recipients with a platform to write or speak about their project can be a valuable addition to such a scheme, as it can help to raise the profile and extend the reach of the work. This could be done in various ways, for example via a blog, podcast series, social media, a departmental website or a newsletter. Often this recognition is as valuable to award recipients as the money they receive.

It seems appropriate to include here a final comment from one of the recipients of a small grant from the ICS, who said, 'Please keep the scheme running - I think it's changing the landscape of PE [public engagement] in UK Classics.' Small grants such as this can, it seems, be transformative for individuals, as well as effecting culture change on both a local and a national level.

\section{Acknowledgements}

With thanks to Greg Woolf for championing the ICS grants scheme, and to Michael Eades and Jen Grove for input relating to internal public engagement grants across UK higher education. 


\section{Notes on the contributor}

Emma Bridges is Staff Tutor and Lecturer in Classical Studies at the Open University, UK. Between 2017 and 2020, she was Public Engagement Fellow in Classics at the Institute of Classical Studies (School of Advanced Study, University of London, UK). She continues to promote and support the sharing of academic research in the arts and humanities with non-specialist audiences.

\section{Conflicts of interest statement}

The author declares no conflict of interest with this work.

\section{Originality statement}

This article is not under consideration for publication elsewhere, and no part of it has previously been published in any form.

\section{References}

Being Human (2021) 'Festival evaluations'. Accessed 9 June 2021. https://beinghumanfestival.org/ festival-evaluations/.

Bridges, E. (2020) 'Announcement: ICS Public Engagement Awards 2020'. ICS blog, 26 August. Accessed 9 June 2021. https://ics.blogs.sas.ac.uk/2020/08/25/announcement-ics-publicengagement-awards-2020/.

British Academy (n.d. a) 'BA Rising Star Engagement Awards'. Accessed 9 June 2021. www.thebritishacademy.ac.uk/funding/ba-rising-star-engagement-awards/.

British Academy (n.d. b) 'Mid-Career Fellowships'. Accessed 9 June 2021. www.thebritishacademy. ac.uk/funding/mid-career-fellowships/.

CUCD (Council of University Classical Departments) (2021) 'Contacts and members'. Accessed 9 June 2021. https://cucd.blogs.sas.ac.uk/contacts-and-members/.

Goldsmiths, University of London (2019) Public Engagement Annual Review 2019. Accessed 9 June 2021. www.gold.ac.uk/media/docs/about/2019-Public-Engagement-Annual-Review(PDF).pdf.

Heritage, Dignity \& Violence Programme (2019) Heritage, Dignity \& Violence Programme 2019: List of Awards. Accessed 9 June 2021. www.thebritishacademy.ac.uk/documents/48/Heritage_ Dignity_and_Violence_Awards_2019.pdf.

ICS (Institute of Classical Studies) (2015) 'Research promotion and facilitation strategy'. Accessed 9 June 2021. https://ics.sas.ac.uk/about-us/research-promotion-and-facilitation-strategy.

ICS (Institute of Classical Studies) (2017) 'Public engagement'. ICS blog. Accessed 9 June 2021 https://ics.blogs.sas.ac.uk/category/public-engagement/.

Kamash, Z. (2018) 'Rematerialising Mosul Museum'. ICS blog, 26 September. Accessed 9 June 2021. https://ics.blogs.sas.ac.uk/2018/09/26/rematerialising-mosul-museum/.

School of Advanced Study, University of London (2019) 'PORT: Postgraduate online research training'. Accessed 9 June 2021. https://port.sas.ac.uk/course/view.php?id=165.

UKRI (UK Research and Innovation) (2020) 'AHRC follow-on funding for impact and engagement'. Accessed 9 June 2021. www.ukri.org/opportunity/ahrc-follow-on-funding-for-impact-andengagement/.

UKRI (UK Research and Innovation) and Research England (2021) 'Research England: Knowledge exchange framework'. Accessed 9 June 2021. https://kef.ac.uk/dashboard.

UKRI (UK Research and Innovation) and AHRC (Arts and Humanities Research Council) (2021) 'Competition statistics'. Accessed 9 June 2021. https://ahrc.ukri.org/about/ competitionstatistics/.

UKRI (UK Research and Innovation) and STFC (Science and Technology Facilities Council) (2018) 'Previous Small Awards'. Accessed 9 June 2021. https://stfc.ukri.org/public-engagement/publicengagement-grants/pe-funding-opportunities/pe-small-awards/.

University of Bath Public Engagement Unit (2021) 'Engage grants'. Accessed 9 June 2021. https://blogs.bath.ac.uk/publicengagement/category/engage-grants/. 
University of Bristol Public Engagement (2021) 'Temple Quarter Engagement Fund'. Accessed 9 June 2021. www.bristol.ac.uk/public-engagement/engagement-opportunities/tq-engagementfund/.

University of Southampton Public Engagement with Research unit (2021) 'Funding:

Public engagement with research (PER) - development funding'. Accessed 9 June 2021.

www.southampton.ac.uk/per/support/funding.page. 